\title{
Correction to: Working Memory Capacity and Relative Clause Attachment Preference of Persian EFL Learners: Does Segmentation Play Any Role?
}

\author{
Mohammad Hadi Mahmoodi ${ }^{1}$ (i) - Hamidreza Sheykholmoluki ${ }^{1}$. \\ Mohammad Reza Zoghipaydar ${ }^{2}$. Saeed Shahsavari ${ }^{3}$
}

Published online: 15 February 2022

(c) Springer Science+Business Media, LLC, part of Springer Nature 2022

\section{Correction to: Journal of Psycholinguistic Research https://doi.org/10.1007/s10936-021-09825-9}

In the original article there are 4 Persian sentences in the article (1 sentence in the procedure and 3 sentences in appendix A) which are scrambled.

This has been corrected in this erratum.

The original article has been updated.

Publisher's Note Springer Nature remains neutral with regard to jurisdictional claims in published maps and institutional affiliations.

The original article can be found online at https://doi.org/10.1007/s10936-021-09825-9.

Mohammad Hadi Mahmoodi mhmahmoodi@basu.ac.ir

Hamidreza Sheykholmoluki

hsheykholmoluki@alumni.ut.ac.ir

Mohammad Reza Zoghipaydar

m.r.zoghipaidar@basu.ac.ir

Saeed Shahsavari

biostat93@gmail.com

1 Department of English Language, Bu-Ali Sina University, Hamedan, Iran

2 Department of Psychology, Bu-Ali Sina University, Hamedan, Iran

3 Epidemiology and Biostatistics, University of Tehran, Tehran, Iran 